\title{
Effect of Ginger Nanoparticles on Hepato-renal Toxicity Induced by Carbon Tetrachloride in Rats
}

\author{
Sanaa Yasser Abd-Elrhman ${ }^{1}$, Hanaa Mostafa Abd El- Fattah ${ }^{1}$, Gehan M. Morsy ${ }^{1}$ \\ and Shimaa Elmasry ${ }^{\star}$ \\ ${ }^{1}$ Department of Biochemistry and Nutrition, Faculty of Women for Arts, Science and Education, \\ Ain Shams University, Cairo, Egypt.
}

Authors' contributions

This work was carried out in collaboration among all authors. Author HMAEF designed the study and wrote the protocol and wrote the first draft of the manuscript. Author SYAE managed the analyses of the study, performed the statistical analysis and managed the literature searches. Authors GMM and SE wrote the protocol, wrote the first draft of the manuscript and performed the statistical analysis. All authors read and approved the final manuscript.

Article Information

DOI: $10.9734 / A R R B / 2020 / v 35 i 730245$

Editor(s):

(1) Dr. Viduranga Y. Waisundara, Australian College of Business \& Technology, Sri Lanka.

Reviewers:

(1) Roberto de Paula do Nascimento, University of Campinas, Brazil. (2) Samira Asgharzade, Shahrekord University of Medical Sciences, Iran. (3) A. B. M. Helal Uddin, International Islamic University Malaysia, Malaysia. Complete Peer review History: http://www.sdiarticle4.com/review-history/59109

Original Research Article

Received 10 May 2020

Accepted 16 July 2020

Published 28 July 2020

\section{ABSTRACT}

Aims: The current study was developed to investigate the influence of ginger (G), ginger nanoparticles (GNPs) and ginger nano-base (GNB) on hepato-renal toxicity induced by carbon tetrachloride $\left(\mathrm{CCl}_{4}\right)$ in rats in comparison with silymarin (SM).

Place and Duration of Study: Department of Biochemistry and Nutrition, Faculty of Women for Arts, Science and Education, Ain Shams University.

Methodology: Fifty-four adult male Sprague-Dawley rats were divided into 6 groups. Group (1): Rats received distilled water orally and injected intraperitoneally (i.p.) with single dose of corn oil (1

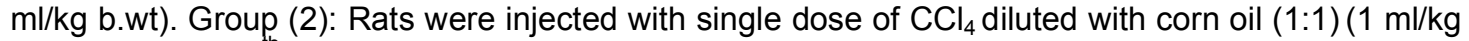
b.wt. i.p.) at the $4^{\text {th }}$ week of experiment. Groups (3), (4) and (5): Rats were orally received $50 \mathrm{mg} / \mathrm{kg}$ b.wt./day of G, GNPs and GNB, respectively for 8 weeks and injected with $\mathrm{CCl}_{4}$ as group 2. Group (6): Rats were orally received $100 \mathrm{mg} / \mathrm{kg} \mathrm{b.wt} \mathrm{/day} \mathrm{of} \mathrm{SM} \mathrm{for} 8$ weeks and injected with $\mathrm{CCl}_{4}$ as group 2.

*Corresponding author: E-mail: shimaa_elmasry33@yahoo.com, Shimaa.elmasry@women.asu.edu.eg; 
Results: Our results documented that injection with $\mathrm{CCl}_{4}$ caused significant increase $(p<0.05)$ in liver function tests [serum alanine aminotransferase (ALT), aspartate aminotransferase (AST) and alkaline phosphatase (ALP) activities], kidney function tests [serum creatinine, urea, uric acid and cystatin $\mathrm{C}$ ] and serum levels of malondialdehyde (MDA), Nitric oxide (NO), tumor necrosis factoralpha (TNF- $\alpha$ ) and interleukin 1 beta $(I L-1 \beta)$. On the other hand, there was a significant decrease $(p<0.05)$ in the serum total antioxidant capacity (TAC), Hepatic catalase (CAT) and superoxide dismutase (SOD) enzymes activity, with histopathological changes in liver and kidneys tissues. Oral administration of G, GNPs, GNB and SM caused an enhancement of liver and kidney function, decreasing serum oxidants and inflammatory markers levels while increasing the activities of antioxidant enzymes, also an improvement of organs histopathological changes was observed.

Conclusion: Our data proved that using ginger in the form of GNPs and GNB are more efficient in ameliorating hepato-renal toxicity induced by $\mathrm{CCl}_{4}$ than using native ginger as evidenced by biochemical analysis and histological examination of liver and kidneys tissues.

Keywords: Carbon tetrachloride; hepatotoxicity; nephrotoxicity; ginger nanoparticles; ginger nanobase; Zingiber officinale; silymarin.

\section{INTRODUCTION}

Liver is the organ engaged in digestion, secretion, biosynthesis, storage of vital nutrients and detoxification of toxicants. Hepatotoxicity is an adverse effects or injuries that occur to the liver due to exposure to hepatotoxins as carbon tetrachloride $\left(\mathrm{CCl}_{4}\right)$, paracetamol, ethanol, galactosamine and anti-tuberculosis drugs [1]. Extravagant intake of these chemicals led to enormous production of free radicals, induce lipid peroxidation and resulting in structural and functional destroys to the membrane and finally causing dangerous toxicity to hepatic cells [2].

Kidneys are the main organs for the secretion of endogenous and exogenous substances. All toxic chemicals and metabolites that are removed by the urine pass through the kidney. Chemicals which induced renal toxicity may occur in the kidney either directly, via biotransformation process in the proximal tubular cells, or indirectly, through the formation of toxic metabolites in the liver which have nephrotoxic effects which leading to acute renal failure [3].

Carbon tetrachloride $\left(\mathrm{CCl}_{4}\right)$ is largely used as an industrial chemical that evaporates simply in the encompassing environment. The liver has a wonderful tendency for $\mathrm{CCl}_{4}$ as it comprises cytochrome $\mathrm{P} 450$ enzyme system which converts $\mathrm{CCl}_{4}$ to trichloromethyl radical $\left(\mathrm{CCl}_{3}{ }^{\circ}\right)$ and peroxy trichloromethyl $\left(\mathrm{CCl}_{3} \mathrm{O}_{2}{ }^{\circ}\right)$ radicals. The mass production of these toxic metabolites may covalently bind to the proteins and lipids of plasma membrane or interact with oxygen which invades unsaturated fatty acids initiating lipid peroxidation. Additionally, override production of free radicals may lead to attrition or deactivation of antioxidant enzymes. These effects cause damage of unsaturated fatty acids and resulting in diverse pathological problems. Pharmacokinetically, metabolic activation of $\mathrm{CCl}_{4}$ happens not only in the liver but also in other organs like lung, heart, testis, brain and kidney $[4,5]$.

Medicinal plants possess the potential of preventing acute and chronic diseases. The protective effect of plants is often maintained through an increased expression of antioxidants and scavenging of free radicals. Antioxidants present in medicinal plants protect against hepatic and renal damage by increasing superoxide dismutase (SOD) and catalase (CAT) activities and lowering lipid peroxidation [6].

Ginger (Zingiber officinale Rosco) a member of the family Zingiberaceae, is traditionally used as a food additive (spice) worldwide to enhance the flavor of food and a common medicinal herb, which contains various phytochemical compounds, as polyphenols including flavonoids and tannins with anti-inflammatory, antioxidant, anti-diabetic, hypo-lipidemic and anticarcinogenic activities. Ginger has antioxidant activity owing to the presence of gingerols, shogaols, zingerone, gingerdiol and zingiberene [7]. Many studies had shown that ginger has hepatoprotective $[7,8]$ and nephroprotective effects $[9,10]$ by improving the liver and kidney biomarkers levels, decreasing inflammation, enhancing the antioxidant activities and prevent lipid peroxidation induced by toxicants.

There are challenges with the application of nanoscale compared with microscale materials. These include higher exposure per unit mass, 
small size: Large surface area ratio, different ways of exposure due to smaller size (i.e. dermal penetration), different distribution to tissues depending on their different size or surface coating, chemistry or particle charge and the properties of a nanoscale material that may alter absorption, digestion, metabolism or excretion in the body. Nanotechnology holds excitement and promise in all areas of science [11].

Plants contain natural nanoparticles which obtained by simple preparation when compared with synthetic nanoparticles which involved financial and potential preparation difficulties [12]. Edible plants nanoparticles can spread from intestine to the liver, so they may have an influential function in treatment pathway and drug delivery to the target cells and enhancement of therapeutic outcomes. Furthermore, nanoparticles present in natural compounds supply a secure carrier for ameliorating drug bioavailability in the cells [11]. Milling herbs to nanoscale increase their exposed surface area, hence, enhancing their active compounds solubility and bioavailability [13].

Many studies demonstrated that ginger nanoparticles (GNPs) improve the antioxidant activity by increasing level of antioxidant enzymes and decrease oxidative stress [14]. Also, it has hepatoprotective effect against liver damage [12] and provide protection against hepatotoxicity and nephrotoxicity induced by acetaminophen in comparison with ginger extract [15], additionally, it prevents nephrotoxicity induced by emamectin benzoate [13].

Synthetic analogs and formulations of ginger have been developed, including combination with polymeric micelles [16] or nanoparticle-based encapsulation by poly-lactic-co-glycolic acids (PLGA) [14] or isolated ginger derived nanoparticles from ginger juice by using high power centrifugation [12], that exhibit greater chemical stability, systemic bioavailability and antioxidant, anti-inflammatory and antitumor activities than naturally occurring ginger. Therefore, we try to develop ginger nano-base particles by milling ginger with sodium bicarbonate [17], to increase ginger solubility and bioavailability.

Silybum marianum is a member of Asteraceae family, it is used to treat liver disease as a hepatoprotective herb. [18]. The hepatoprotective effect of silymarin is attributed to its dosedependent antioxidant effect. This impact is intermediated by catching the free radicals, reducing production of ROS and attenuating the lipid peroxidation. Other mechanisms include anti-apoptotic and anti-inflammatory actions via intervention with nuclear factor kappa-B (NF-kB), alternation of inducible nitric oxide (INOS) and decreases in cyclooxygenase-2 (COX-2) expression [19]. Silymarin also has renoprotective mediator against nephrotoxic agents because of its antioxidant, anti-inflammatory and anti-apoptotic properties [20,21].

The present study was conducted to assess the influence of ginger (G), ginger nanoparticles (GNPs) and ginger nano-base (GNB) on liver and kidney toxicity induced by carbon tetrachloride $\left(\mathrm{CCl}_{4}\right)$ in rats.

\section{MATERIALS AND METHODS}

\subsection{Chemicals}

Carbon tetrachloride (99\%) was purchased from El-Gomhoria Company for Chemicals and Drugs; Cairo, Egypt. Silymarin (Silybum marianum) was purchased from Chemical Industries Development Company; Cairo, Egypt.

\subsection{Plant Material}

Fresh ginger rhizome roots (Zingiber officinale Roscoe) was purchased from Ministry of Agriculture; Giza, Egypt.

\subsection{Experimental Animals}

Adult male albino rats (Sprague -Dawley strain) weighing150-180 g were obtained from animal Breeding House of National Research Center (NRC); Giza, Egypt. Animals were handled in this study in accordance with the Principles of laboratory animal care" (NIH publication No. 8523 , revised 1985 . The experimental animals were housed individually in metallic cages with good ventilation and under conventional condition (22 $\pm 3^{\circ} \mathrm{C}$ and natural light/dark cycle). All rats were received the standard commercial diet (obtained from National Research Center; Giza, Egypt) and water ad libitum for 7 days (acclimatization period) before starting the experiment.

\subsection{Preparation of Ginger (G), Ginger Nanoparticles (GNPs) and Ginger Nano-Base (GNB)}

Ginger rhizome roots were washed several times with water, cut into small pieces, then dried by 
oven at $50^{\circ} \mathrm{C}$ for 2 hours, the dried ginger was ground to get fine ginger powder utilizing mixer and stored in sterilized glass container at room temperature for future use $[22,14]$.

To prepare ginger nanoparticles (GNPs) about $50 \mathrm{mg}$ of ginger powder was ground by mechanical ball milling [23] utilizing a planetary ball mill (Retsch PM 400, Germany) at (350 round/Sec) for 16 hours. The main episode in mechanical milling is the ball-powder-ball crashing, where the dehydrated powder was restricted between the crashed balls throughout milling with high speed forming fine powder in nano scales [22].

Zingiber officinale and turmeric (curcuma longa) are in the same botanical family (Zingiberacae) and these plants have similar molecules. Also [6]-shogaol and [6]-gingerol from ginger have structural similarity with curcumin. So, they might have similar antioxidant and anti-inflammatory properties [24]. So that we applied the same method of preparation of curcumin nano-base in ginger to produce ginger nano-base, in an attempt for increasing the solubility and bioavailability of ginger as occur with curcumin nano-base.

For preparation of basic ginger nanoparticles (GNB), $50 \mathrm{mg}$ fine ginger powder with low solubility in water was mixed with $50 \mathrm{mg}$ sodium bicarbonate buffer, then ground by mechanical ball mill using a planetary ball mill (Retsch PM 400, Germany) at (350 round/Sec) for $15 \mathrm{hrs}$. The color of ginger changed from yellow to yellowish white as a result of the ginger sodium salt formation [17].

\subsection{Evaluation of Ginger Nanoparticles (GNPs) Size by Using DLS}

Dynamic light scattering (DLS) is an efficient method used to determine the nanoparticle size, size distribution and shape of particles in suspension through the brownian motion and doppler shift induced by a laser beam. The ginger nanoparticles or ginger nano-base was diluted with filtered de-ionized water to produce suspended solution and then placed in Elmasonic S $15 \mathrm{H}$ apparatus at $20-25^{\circ} \mathrm{C}$ for 3 $\mathrm{min}$ to vibrate and distribute the nanoparticles in solution, then the solution was left for $10 \mathrm{~min}$ to allow stability of nanoparticles, after that the solution transferred to Malvern Zetesizer Nano ZS Apparatus to measure the nanoparticles size.

\subsection{Determination of Total Phenols and Total flavonoids Content in Ginger}

Total phenols were determined in ginger ethanolic extract by using the Folin-Ciocalteu method, while total flavonoids were determined by aluminum chloride colorimetric method according to Singleton et al. and Arvouet-Grand et al., respectively $[25,26]$.

\subsection{Determination of Main phenolic Compounds in Ginger}

The concentration of [6]-gingerol, [8]-gingerol, [6]-shogol, [10]-gingerol, [8]-shogol and [10]shogol in ginger was determined by using HPLC technique according to Cafino et al. [27].

\subsection{Induction of Hepatotoxicity and Nephrotoxicity}

Hepatotoxicity and nephrotoxicity were induced in rats by intraperitoneal (i.p) injection with single dose of carbon tetrachloride [1 $\mathrm{ml} / \mathrm{kg}$ b.wt)] which diluted with corn oil (1:1) immediately before administration to rats at the end of the $4^{\text {th }}$ week of the experiment [28].

\subsection{Experimental Design}

Fifty-four adult Sprague-Dawley rats were divided into six groups each of nine rats. One $\mathrm{g}$ of G, GNPs and GNB powder were separately suspended in $100 \mathrm{ml}$ distilled water immediately before administration to rats. Olive oil has some protective effect on liver injury; hence, corn oil may be a better option as a vehicle for $\mathrm{CCl}_{4}$

Rats were treated as follows: Group I:Normal control, rats were orally received distilled water by gastric tube daily for 8 weeks; Group II: $\mathrm{CCl}_{4}$, rats were orally received distilled water daily for 8 weeks, and injected intraperitoneally (i.p.) with single dose of $\mathrm{CCl}_{4}(1 \mathrm{ml} / \mathrm{kg} / \mathrm{b} . \mathrm{wt}$.) in corn oil $(1: 1)$ at the end of fourth week. Groups (III), (IV), (V): Rats were orally given G, GNPs and GNB (50 mg /kg b.wt. /day), respectively for 8 weeks, and injected with $\mathrm{CCl}_{4}$ as mentioned in group II. Group VI: (SM), rats were orally received SM (100 mg /kg b.wt. /day) for 8 weeks and injected with $\mathrm{CCl}_{4}$ as mentioned in group II.

\subsection{Handling of Blood and Tissue Samples}

At the end of empirical interval and after 12 hours fasting, rats were sacrificed under anesthesia, 
and blood samples were collected from hepatic portal vein. Serum was obtained by centrifugation of blood at $3000 \mathrm{rpm}$ for 15 minutes after that stored frozen at $-20^{\circ} \mathrm{C}$ for biochemical tests. Liver and kidneys were separated and plotted free from adhering blood, washed with cold physiological saline $(0.9 \%$ $\mathrm{NaCl}$ ) and dried between filter papers. Part of liver and kidneys tissues were obtained and immediately preserved in $10 \%$ buffered formalin solution ( $\mathrm{pH} 7.4)$ for microscopic examination, the other part was kept frozen at $\left(-20^{\circ} \mathrm{C}\right)$ till used for biochemical analysis.

\subsection{Biochemical Assessment}

\subsubsection{Determination of liver function parameters}

Serum alanine aminotransferase (ALT) and aspartate aminotransferase (AST) activities were determined using colorimetric kit according to Murray [29], alkaline phosphatase (ALP) activity was determined by colorimetric method using Spectrum Diagnostic kit according to Belfield and Goldberg [30].

\subsubsection{Determination of kidney function biomarkers}

The determination of serum creatinine was performed according to kinetic colorimetric method [31]. Serum urea and uric acid were determined using enzymatic colorimetric method according to Kaplan [32] and Fossati et al. [33], respectively. Serum cystatin $C$ was determined based on sandwich ELISA assay technique according to the method described by Pergande and Jung [34].

\subsubsection{Assessment of inflammatory markers}

Serum tumor necrosis factor- alpha (TNF- $\alpha$ ) and interleukin 1 beta (IL-1 $\beta$ ) levels were performed following sandwich ELISA technique using Rat ELISA kit according to Dowlati et al. [35] and Garabedian et al. [36], respectively.

\subsubsection{Assessment of antioxidant and oxidative stress status}

Serum total antioxidant capacity (TAC) level was determined by enzymatic colorimetric method according to koracevic et al. [37]. For assessment of hepatic CAT and SOD, the liver tissue was perfused with a phosphate buffer saline (PBS) solution, $\mathrm{pH} 7.4$, containing $0.16 \mathrm{~g} /$ $\mathrm{ml}$ heparin to remove any blood cell and clots. One gram of tissue was homogenized in $10 \mathrm{ml}$ cold buffer (i-e, $100 \mathrm{mM}$ potassium phosphate, $\mathrm{pH}$ 7.0, containing $2 \mathrm{mM}$ EDTA). Then centrifuged at $4000 \mathrm{rpm}$ for 15 minutes at $4 \mathrm{o} \mathrm{C}$ and the supernatant was removed. Hepatic CAT and SOD activities were determined colorimetrically using standard kit as described by Aebi [38] and Nishikimi et al. [39], respectively. Serum NO and MDA levels were determined by photometric method using standard kit according to Montgomery and Dymock [40] and Satoh [41], respectively.

\subsection{Microscopic Examination of Liver and Kidneys Tissues}

Tissue samples from liver and kidneys were fixed in $10 \%$ formalin solution for $24 \mathrm{hrs}$. After fixation, tissues were washed and dehydrated, then inserted in paraffin wax. The embedded tissues were sectioned to $5 \mu \mathrm{m}$ thick sections were subjected to microscopic examination. Hematoxylin and Eosin ( $\mathrm{H}$ and $\mathrm{E})$ stains were used with power magnification $X 400$ [42].

\subsection{Statistical Analysis}

The data were statistically analyzed by one-way (ANOVA) and Post Hoc Tukey. A difference was considered significant when $p$ was less than or equal to 0.05 . The data was analyzed using (SPSS) statistics version 16.0 according to [43].

\section{RESULTS AND DISCUSSION}

\subsection{Characterization of Ginger Nanoparticles (GNPs) and Ginger Nano-base (GNB)}

The particle size of ginger nanoparticles and ginger nano-base were determined and evaluated according to size distribution by number. Fig. 1 shows that $99.5 \%$ of GNPs size was reached to $38.29 \mathrm{~nm}$ while Fig. 2 demonstrates that $99.9 \%$ of GNB size was reached to $22.05 \mathrm{~nm}$.

Nanotechnology allow scientists to output nanoscale particles. The nanoparticles can effortlessly go among blood vessel walls, or even insert themselves into most of body cells when they are smaller than $20 \mathrm{~nm}$ or $50 \mathrm{~nm}$ which makes them an excellent choice for specialized drugs to be used in targeted delivery of plentiful doses of chemotherapeutic agents [44]. 
In the study of Mehanna et al., the ginger powder was ground using planetary ball mill device for 4 hours at $550 \mathrm{rpm}$ to obtain ginger nanoparticles and the size of nanoparticles was evaluated by using DLS. They found that, $98.5 \%$ of GNPs reach to $75.59 \mathrm{~nm}$ [13].

\subsection{Total Phenols and Flavonoids Content of Ginger}

The data presented in (Table 1) indicate the total phenols expressed as $\mathrm{mg}$ of gallic acid equivalent (mg GAE /100 g of ginger) and total flavonoids expressed as $\mathrm{mg}$ of quercetin equivalent (mg QE /100 $\mathrm{g}$ of ginger). The results showed that each $100 \mathrm{~g}$ of the tested extract contains $2171.2 \mathrm{mg}$ as gallic acid equivalent of total phenols and $343.75 \mathrm{mg}$ as quercetin equivalent of total flavonoids.

Phenolic compounds are one of the principle groups of secondary metabolites in plants, they have antioxidants and anti-inflammatory properties, regulate enzyme activity and gene expression [45]. Wijayanti et al. (2018) reported that the ethanol solvent is able to bind secondary metabolite compounds in the sample, they revealed that total phenolic content of $96 \%$ ethanolic extract of ginger was $485.1847 \mathrm{mg}$ GAE/100 $\mathrm{g}$ dry weight [46].

Flavonoids constitute the largest percent of dietary polyphenols (more than $60 \%$ ). Flavonoids apply their antioxidative activity by efficiently scavenging numerous free radical such as superoxide anion and peroxynitrite, by modulating oxidative stress-mediated enzyme activity and by catching the transition metals associated with processes of radical production [47]. Shirin and Prakash (2010) demonstrated that flavonoid content of $80 \%$ ginger ethanolic extract is $0.352 \mathrm{~g}$ quercetin $/ 100 \mathrm{~g}$ ginger extract [48].

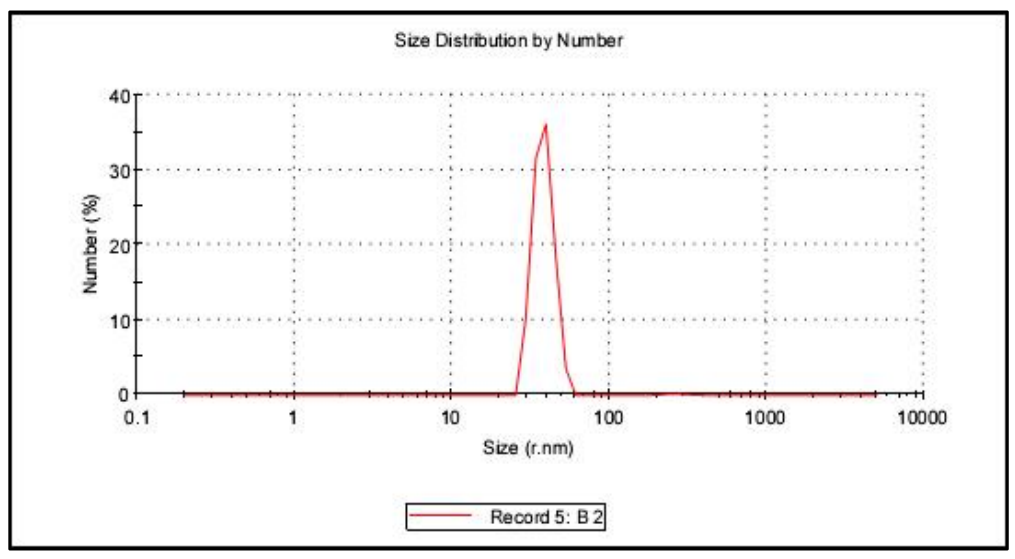

Fig. 1. Particle size of ginger nanoparticles (GNPs) was measured by dynamic light scattering (DLS) technique using a Malvern Zetesizer Nano ZS Apparatus

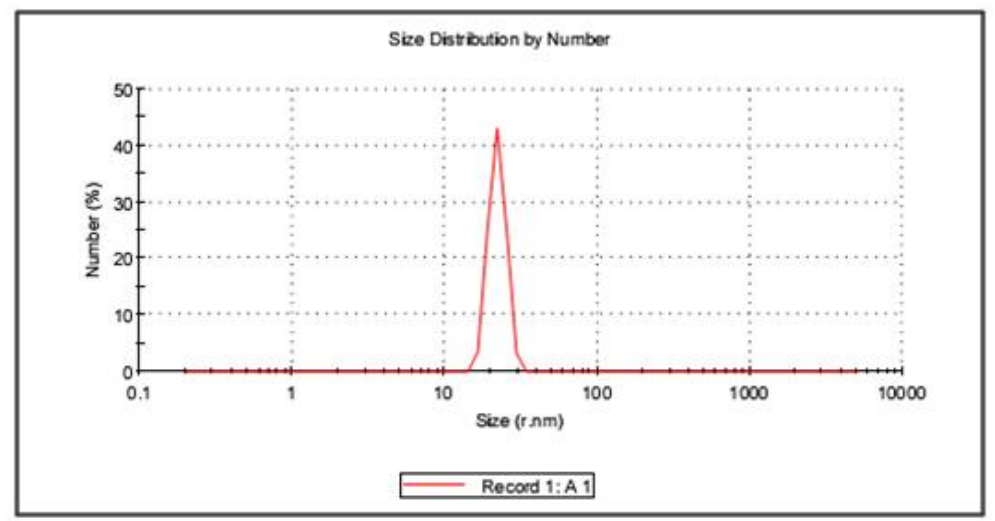

Fig. 2. Particle size of ginger nano-base (GNB) was measured by dynamic light scattering (DLS) technique using a Malvern Zetesizer Nano ZS Apparatus 
Table 1. Total flavonoid and phenolic contents of ginger ethanolic extract

\begin{tabular}{ll}
\hline Active components & Value $/ \mathbf{1 0 0} \mathrm{g}$ of ginger \\
\hline Total phenols & $2171.2 \mathrm{mg}$ as GAE \\
Total flavonoids & $343.75 \mathrm{mg}$ as QE \\
\hline
\end{tabular}

\subsection{The Concentration of Main Phenolic Compounds of Ginger}

Analysis of ginger extract using ultra highperformance liquid chromatography detected the presence of many active phenolic compounds. Fig. (3) indicate the percentage of main phenolic compounds in ginger extract as [6]-gingerol, [8]gingerol, [6]-shogaol, [10]-gingerol, [8]-shogaol and [10]-shogaol. It is clear that [6]-gingerol represent the highest percentage $(33.48 \%)$ of ginger phenolic components, while [10]-shogaol $(2.03 \%)$ and [8]-shogaol $(1.09 \%)$ were found in the lowest percentage.

\subsection{Liver Function Biomarkers in Experimental Groups Intoxicated by $\mathrm{CCl}_{4}$}

A single dose of $\mathrm{CCl}_{4}$ injection ( $1 \mathrm{ml} / \mathrm{kg}$ b.wt.) resulted in hepatic damage as indicated by significant increase in serum ALT, AST and ALP enzymes activity (Table 2). Administration of $G$, GNPs, GNB and SM to $\mathrm{CCl}_{4}$ - administered rats significantly $(P \leq 0.05)$ lowered the activity of liver enzymes when compared with $\mathrm{CCl}_{4}$ group. The most significant ameliorating effect on serum
ALT and ALP activities was seen in GNB treated group, while GNPs and SM treated groups showed the most significant enhancement in serum AST activity comparing to $\mathrm{CCl}_{4}$ group.

$\mathrm{CCl}_{4}$ intoxication is the experimental model of choice for induction of liver injury for many scientists all over the world. The damage of hepatocytes occurred by $\mathrm{CCl}_{4}$ was suggested to be due to the fact that $\mathrm{CCl}_{4}$ is metabolized by cytochrome P450 oxygenase enzyme system, producing trichloromethyl radical $\left(\mathrm{CCl}_{3}{ }^{\circ}\right.$ ) and trichloromethyl peroxy radical $\left(\mathrm{CCl}_{3} \mathrm{O}_{2}{ }^{\circ}\right)$ which invade lipids in the plasma membrane, resulting in initiation of fatty acids of phospholipid peroxidation and increase in MDA level with depletion in antioxidant enzymes, and finally leakage of plasma membrane and release of liver enzymes from hepatocyte [49].

The marked elevation of serum ALT, AST and ALP in $\mathrm{CCl}_{4}$ treated group in our study indicates severe damage to hepatic tissue. These findings were in agreement with previous studies which indicated that administration of single dose of $\mathrm{CCl}_{4}(1 \mathrm{ml} / \mathrm{kg}$ B.W) significantly increased the serum level of ALT, AST and ALP enzymes in rats $[49,50,51]$.

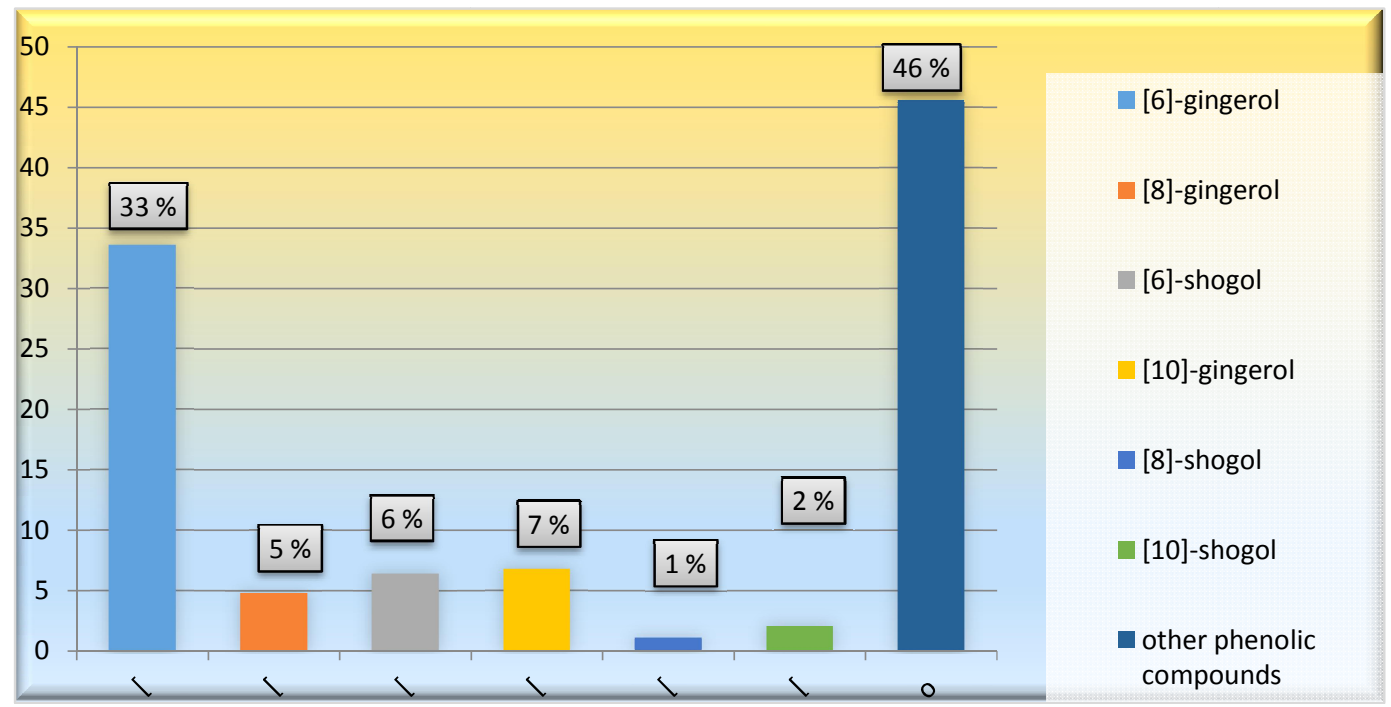

Fig. 3. The percentage of main phenolic constituents of ginger that was indicated in the percentage of total phenols 
Table 2. Serum alanine aminotransferase (ALT), aspartate aminotransferase (AST) and alkaline phosphatase (ALP) activities in the experimental groups (mean $\pm \mathrm{SE}$ ).

\begin{tabular}{|c|c|c|c|}
\hline Parameters/Groups & ALT (U/I) & AST (U/I) & ALP (U/I) \\
\hline Control & $11.049 \pm 0.062^{\mathrm{d}}$ & $16.00 \pm 0.543^{\mathrm{e}}$ & $106.81 \pm 0.533^{\mathrm{d}}$ \\
\hline $\mathrm{CCl}_{4}$ & $18.197 \pm 0.072^{\mathrm{a}}$ & $31.85 \pm 0.169^{a}$ & $180.19 \pm 1.181^{\mathrm{a}}$ \\
\hline $\mathrm{CCl}_{4}+\mathrm{G}$ & $13.978 \pm 0.139^{b}$ & $25.08 \pm 0.126^{b}$ & $120.75 \pm 0.657^{\mathrm{b}}$ \\
\hline $\mathrm{CCl}_{4}+$ GNPs & $11.818 \pm 0.096^{c}$ & $23.12 \pm 0.034^{c}$ & $115.67 \pm 0.744^{c}$ \\
\hline $\mathrm{CCl}_{4}+\mathrm{GNB}$ & $11.053 \pm 0.139^{d}$ & $24.48 \pm 0.255^{b}$ & $101.01 \pm 0.919^{\mathrm{e}}$ \\
\hline $\mathrm{CCl}_{4}+\mathrm{SM}$ & $11.582 \pm 0.064^{c}$ & $21.59 \pm 0.578^{d}$ & $106.47 \pm 0.940^{d}$ \\
\hline
\end{tabular}

Natural products contribute to the prevention, limitation and treatment of liver diseases. Ginger and silymarin are among the natural products with antioxidant effects so that they can be used to protect liver from hepatotoxicity [52]. In agreement with our finding, pretreatment with ginger extract $\left(250 \mathrm{mg} / \mathrm{kg}\right.$ B.W) with $\mathrm{CCl}_{4}$ (I $\mathrm{ml} / \mathrm{kg} \mathrm{B.W}$ ) caused significant decrease in serum $\mathrm{ALT}, \mathrm{AST}$ and ALP, reversing the effect of $\mathrm{CCl}_{4}$ due to the presence of gingerols and shogoals bioactive components that act as free radical scavenger and protect the liver cell membrane from oxidation and damage [53].

The nanoparticles of edible plant are highly reluctant to digestion by gastric, intestinal pancreatic juices and bile extract. Considerable quantities of plant nanoparticles are taken up by intestinal macrophages and stem cells. So that, the molecules involving lipids and RNA from plant nanoparticles may also possess an effect on the targeted cells positioned in the gut and liver [54]. The present study demonstrated that administration of ginger in the form of GNPs and GNB for 8 weeks exhibited more protection against $\mathrm{CCl}_{4}$ - induced liver and kidney toxicity in rats in relative to native ginger.

In line with our result, Bakr et al. (2019) reported that administration of aqueous ginger extract (120 $\mathrm{mg} / \mathrm{kg} \mathrm{B.W}$ ) and GNPs (120 mg/kg B.W) with acetaminophen caused significant decrease in serum ALT and AST activities and amelioration of microscopic examination of liver tissues as compared to acetaminophen group. The effect of GNPs on keeping live function tests was better than that of ginger extract [15].

Our results are also similar to the previous findings which showed that oral administration of ginger derived nanoparticles (GDNPs) with single dose of ethanol protect against alcohol-induced liver injury through reduction of $A L T$ and $A S T$ activities compared to ethanol group [55].

Ginger can protect liver due to its antioxidant properties which act as scavengers of free radicals, suppress lipid peroxidation and DNA destruction, that could ameliorate hepatocyte structure and function. It causes stabilization to the cell membrane, due to the presence of proteins and small peptide [7].

Silymarin was used in this study as a reference herbal drug for its well-identified hepatoprotective mechanism. The hepatoprotective actions of silymarin have been previously imputed to its antioxidant properties $[56,57,58,59]$. It was reported that silymarin inhibits liver injury by maintaining the integrity of the plasma membrane, inhibits the secretion of liver enzymes in blood, and suppresses apoptosis in the hepatocytes [60].

\subsection{Kidney Function Biomarkers in Experimental Groups Intoxicated by $\mathrm{CCl}_{4}$}

Our results revealed that rats treated with $\mathrm{CCl}_{4}$ exhibited significant $(P \leq 0.05)$ increase in the serum urea, creatinine, uric acid and cystatin $\mathrm{C}$ levels compared to the control group (Table 3).

The treated groups showed a significant decrease $(P \leq 0.05)$ in the serum levels of creatinine, urea and cystatin $C$ as compared to $\mathrm{CCl}_{4}$, with no significant difference between GNPs, GNB and SM groups. There was a significant $(P \leq 0.05)$ decrease in serum uric acid level in all treated groups except $\mathrm{CCl}_{4}+\mathrm{G}$, which has no significant difference in comparison with $\mathrm{CCl}_{4}$ group. The most effective treatment was appeared in GNPs comparing with GNB and SM. 
It was demonstrated that acute subjection to $\mathrm{CCl}_{4}$ resulted in a significant drop in the renal function tests, which was noted through an increase in serum creatinine, urea and uric acid levels, this was in accordance with the present results $[3,6]$. A good explanation for $\mathrm{CCl}_{4}$ induced nephrotoxicity was introduced by Akram et al. (2019), who suggested that $\mathrm{CCl}_{4}$ - reno toxic mechanism is almost like that of the liver, but cytochrome P-450 system is located in the renal cortex so $\mathrm{CCl}_{4}$ shows a high tendency to it. Renal toxicity caused a fast decay in the kidney functions that is principally ascribed to decline in glomerular filtration rate (GFR) and diminish the kidney capability to excrete the toxic metabolites formed in the body, resulting in abnormal detention of renal parameters [61].

Cystatin $C$ is a non-glycosylated protein which produced in all nucleated cells, it is refined by glomeruli and then metabolized in proximal renal tubule cells following megalin-mediated endocytosis. Cys- $\mathrm{C}$ is the fundamental protector of the glomerular membrane from destruction by cysteine proteinases. The changed glomerular filtration rate also identified by the raised serum cystatin $C$ because it is an preliminary marker of kidney problem than familiar markers (e.g. creatinine) and can reveal mild to moderate kidney problems [62]. In our study, the elevated level of Cys-C in $\mathrm{CCl}_{4}$ intoxicated rats indicated impairment in kidney function.

Our results were confirmed by previous study which documented that administration of aqueous ginger extract $(500 \mathrm{mg} / \mathrm{kg} / \mathrm{day})$ along with $\mathrm{CCl}_{4}$ resulted in a significant decrease in the serum levels of creatinine, urea and uric acid compared to $\mathrm{CCl}_{4}$ group. The protective effect of ginger may be due to to its antioxidant properties. Also, ginger contains vitamins A, B, C and $E$, magnesium and other trace elements, which behave as antioxidants against free radicals induced kidney injury [63]. Moreover, the existence of polyphenols and flavonoids in the ginger extract might be responsible for the antioxidant reno-protective activities and the lowering of elevated values of kidney function indices [64].

In agreement with our results, Bakr et al. (2019) reported that administration of aqueous ginger extract $(120 \mathrm{mg} / \mathrm{kg} \mathrm{B.W})$ and GNPs $(120 \mathrm{mg} / \mathrm{kg}$ B.W) with acetaminophen caused a significant decrease in serum urea and uric acid levels and enhancement of the kidney tissues as compared to acetaminophen group [15].
Silymarin has antioxidant and anti-inflammatory properties that may provide protective role against nephropathic processes. EL. Sayed et al. confirmed that administration of silymarin (200 $\mathrm{mg} / \mathrm{kg}$ orally) with $\mathrm{CCl}_{4}$ caused significant decrease in serum level of creatinine and urea compared to $\mathrm{CCl}_{4}$ group [65].

\subsection{Inflammatory Biomarkers in Experimental Groups Intoxicated by $\mathrm{CCl}_{4}$}

It was observed from the present results that the mean value of serum TNF- $\alpha$ and IL- $1 \beta$ in $\mathrm{CCl}_{4}$ group were significantly $(P \leq 0.05)$ higher compared to control group. Administration of G, GNPs, GNB and SM attenuated the inflammatory effect of $\mathrm{CCl}_{4}$ which indicated by significant $(P \leq$ $0.05)$ reduction in TNF- $\alpha$ and IL-1 $\beta$ levels comparing to $\mathrm{CCl}_{4}$-administrated group. Treatment with GNB has the best ameliorating effect on serum TNF- $\alpha$ level, while, GNPs and SM have the most enhancement effect on serum IL-1 $\beta$ level than other handlings comparing to $\mathrm{CCl}_{4}$ group (Table 4).

In the current study, $\mathrm{CCl}_{4}$-treated rats exhibited severe inflammation and subsequently an overproduction of TNF- $\alpha$ and IL- $\beta$. It was reported that intraperitoneal injection with $(5 \mathrm{ml}$ $/ \mathrm{kg} \mathrm{B.W}$ ) of $\mathrm{CCl}_{4}$ resulted in significant raise in serum TNF- $\alpha$ and IL-1 $\beta$ levels which led to systemic inflammatory response syndrome. Absolute liberation of inflammatory agents can cause tissue injury. $\mathrm{CCl}_{4}$ stimulates macrophages and increases inflammatory cytokines that in turn intermediate the inflammatory responses and inflammation of liver. TNF- $\alpha$ trigger lymphocytes and neutrophils to motivate liberation of IL-1 $\beta$ [66].

Hepatic inflammation followed by liver injury developed by $\mathrm{CCl}_{4}$-administration is attributed to activation of kupffer cells that lead to releasing reactive oxygen intermediates. ROS stimulate $\mathrm{NF}-\mathrm{KB}$ and lead to massive expression of TNF- $\alpha$ and IL-1 $\beta$. These cytokines expressed in the $\mathrm{CCl}_{4}$-induced inflammatory process is related to the evolution of fibrosis. Protection from hepatic injury caused by $\mathrm{CCl}_{4}$ is associated with suppression of TNF- $\alpha$ level. So that, the inhibition of proinflammatory cytokines is used as indication for anti-inflammatory effect [67].

The active phenolic components of ginger have a strong anti-inflammatory property through suppression of TNF- $\alpha$ and IL-1 $\beta$ via inhibition of 
Table 3. Serum creatinine, urea, uric acid and cystatin C (Cys- C) levels in the experimental groups

\begin{tabular}{|c|c|c|c|c|}
\hline Parameters/Groups & Creatinine (mg/dl) & Urea (mg/dl) & Uric acid (mg/dl) & Cys - C (pg/ml) \\
\hline Control & $0.715 \pm 0.012^{c}$ & $39.675 \pm 0.499^{b}$ & $1.634 \pm 0.025^{d}$ & $0.962 \pm 0.015^{c}$ \\
\hline $\mathrm{CCl}_{4}$ & $1.078 \pm 0.006^{a}$ & $49.300 \pm 0.653^{a}$ & $2.989 \pm 0.038^{a}$ & $4.108 \pm 0.126^{a}$ \\
\hline $\mathrm{CCl}_{4}+\mathrm{G}$ & $0.771 \pm 0.011^{\mathrm{b}}$ & $38.901 \pm 0.526^{b}$ & $2.945 \pm 0.053^{a}$ & $1.231 \pm 0.017^{\mathrm{bc}}$ \\
\hline $\mathrm{CCl}_{4}+\mathrm{GNPs}$ & $0.726 \pm 0.024^{c}$ & $37.261 \pm 0.271^{c}$ & $2.212 \pm 0.038^{c}$ & $1.104 \pm 0.018^{\mathrm{b}}$ \\
\hline $\mathrm{CCl}_{4}+\mathrm{GNB}$ & $0.730 \pm 0.006^{c}$ & $37.571 \pm 0.374^{c}$ & $2.692 \pm 0.079^{b}$ & $1.159 \pm 0.027^{\mathrm{b}}$ \\
\hline $\mathrm{CCl}_{4}+\mathrm{SM}$ & $0.691 \pm 0.015^{c}$ & $37.259 \pm 0.330^{c}$ & $2.799 \pm 0.019^{b}$ & $1.194 \pm 0.038^{b}$ \\
\hline
\end{tabular}


COX-2 and NF- KB [68]. In the study performed by Mansour et al., (2019), treatment with ginger powder (108 or $216 \mathrm{mg} / \mathrm{kg} \mathrm{B.W/day)} \mathrm{led} \mathrm{to}$ significant decrease in hepatic IL- $1 \beta$ and TNF- $\alpha$ as compared with di-ethylnitrosamine group (the same effect as $\mathrm{CCl}_{4}$ ) [68]. They suggested that the active components of ginger ([6]-gingerol and [6]-paradol) possess a strong anti-inflammatory activity [17].

GNPs were reported to reduce the chronic liver and kidney inflammation in rats by reducing the pro-inflammatory cytokines (TNF- $\alpha$ and IL-1 $\beta$ ) expression [69]. It was illustrated also that silymarin has anti-inflammatory properties which enable it to recurred the inflammation caused by $\mathrm{CCl}_{4}[51,70]$.

\subsection{Oxidative Biomarkers in Experimental Groups Intoxicated by $\mathrm{CCl}_{4}$}

Administration of $\mathrm{CCl}_{4}(1 \mathrm{ml} / \mathrm{kg}$ b.wt.) was remarkably $(P \leq 0.05)$ elevated the oxidative biomarkers, MDA and NO levels, comparing to normal group. Co-administration of G, GNPs, GNB and SM with $\mathrm{CCl}_{4}$ caused significant decline in serum MDA and NO relative to $\mathrm{CCl}_{4}$ group. The supplementation with GNB caused the best improvement in the MDA level, while GNPs has the best influence on NO level when compared with toxic group (Table 5).

Our results revealed that $\mathrm{CCl}_{4}$ caused increase in MDA level, the final product of tissue lipid peroxidation and stimulates the production of reactive nitrogen products as nitrite and NO, which afterward interacts with the superoxide anion to produce a peroxynitrite (ONOO2), a cytotoxic oxidant. Peroxynitrite caused DNA and mitochondrial membrane damage that evokes the process of the membrane fatty acid peroxidation or led to apoptosis. In corresponding to our study, it was reported that intraperitoneal injection with $\mathrm{CCl}_{4}$ lead to significant increase in serum NO and MDA levels. These findings assure that $\mathrm{CCl}_{4}$ is a xenobiotic, caused oxidative stress and may injure hepatic cells [52].

It was illustrated that administration of ginger suspension (300 mg/kg/day) and $\mathrm{CCl}_{4}(2 \mathrm{ml} / \mathrm{kg}$ B.W/ twice weekly) resulted in significant declines in serum MDA and NO levels compared to $\mathrm{CCl}_{4}$ group . The beneficial effect of ginger is owing to the bioactive constituents like gingerols and shogaols that exhibited strong antioxidant activity. Gingerol inhibited lipid peroxidation induced by the ferric chloride-ascorbate system. Moreover, novel glucosides related to gingerdiol from ginger have antioxidant activity [71].

Additionally, Administration of silymarin and $\mathrm{CCl}_{4}$ $(2 \mathrm{ml} / \mathrm{kg} \mathrm{B.W})$ resulted in significant decrease in serum MDA and NO levels comparing to $\mathrm{CCl}_{4}$ group. This effect was attributed to the antioxidant properties of silymarin and it is ability to prevent lipid peroxidation and cell damage by oxidants [51].

\subsection{Serum Total Antioxidant Capacity Level and Hepatic Antioxidant Enzymes Activity in Experimental Groups Intoxicated by $\mathrm{CCl}_{4}$}

Table (6) clarifies that the serum TAC level and antioxidant defense enzymes (CAT and SOD) activity was significantly $(P \leq 0.05)$ declined in response to injection with $\mathrm{CCl}_{4}$ compared to control group. Additionally, it was detected that serum TAC was significantly increased by treatment with SM, GNB, GNPs and G, respectively according to their effect, comparing to $\mathrm{CCl}_{4}$ group. The activity of hepatic CAT and SOD was significantly raised in all treated groups comparing with $\mathrm{CCl}_{4}$ group, the most significant increase in hepatic CAT levels was found in GNPs in relative to other treated groups.

Table 4. Serum tumor necrosis factor- alpha (TNF- $\alpha$ ) and interleukin- 1 beta (IL-I $\beta$ ) levels in the experimental groups (mean $\pm \mathrm{SE}$ )

\begin{tabular}{lll}
\hline Parameters/Groups & TNF- $\alpha(\mathbf{p g} / \mathbf{m l})$ & IL-I $\beta(\mathbf{p g} / \mathbf{m l})$ \\
\hline $\mathrm{Control}$ & $17.211 \pm 0.164^{\mathrm{e}}$ & $33.657 \pm 0.304^{\mathrm{e}}$ \\
$\mathrm{CCl}_{4}$ & $92.969 \pm 0.428^{\mathrm{a}}$ & $116.45 \pm 0.159^{\mathrm{a}}$ \\
$\mathrm{CCl}_{4}+\mathrm{G}$ & $63.594 \pm 0.639^{\mathrm{b}}$ & $74.451 \pm 0.349^{\mathrm{b}}$ \\
$\mathrm{CCl}_{4}+\mathrm{GNPs}$ & $63.033 \pm 0.441^{\mathrm{b}}$ & $69.442 \pm 0.827^{\mathrm{cd}}$ \\
$\mathrm{CCl}_{4}+\mathrm{GNB}$ & $46.742 \pm 0.323^{\mathrm{d}}$ & $70.869 \pm 1.118^{\mathrm{c}}$ \\
$\mathrm{CCl}_{4}+\mathrm{SM}$ & $55.912 \pm 0.468^{\mathrm{c}}$ & $68.916 \pm 0.318^{\mathrm{d}}$ \\
\hline
\end{tabular}

There is no significant difference between means have the same letters in the same column, $n=9$ rats,

$\left(P \leq\right.$ 0.05). $\mathrm{CCl}_{4}$ : Carbon tetrachloride, G: Ginger, GNPs: Ginger nano particles, GNB: Ginger nano- base, SM: Silymarin 
Table 5. Serum nitric oxide (NO) and malondialdhyde (MDA) levels in experimental groups (mean \pm SE)

\begin{tabular}{lll}
\hline Parameters/Groups & $\mathbf{N O}(\boldsymbol{\mu m o l} / \mathbf{L})$ & MDA $(\mathbf{n m o l} / \mathbf{~ m l})$ \\
\hline Control & $0.392 \pm 0.018^{\mathrm{f}}$ & $3.381 \pm 0.074^{\mathrm{d}}$ \\
$\mathrm{CCl}_{4}$ & $3.457 \pm 0.074^{\mathrm{a}}$ & $8.111 \pm 0.238^{\mathrm{a}}$ \\
$\mathrm{CCl}_{4}+\mathrm{G}$ & $1.896 \pm 0.116^{\mathrm{b}}$ & $4.877 \pm 0.186^{\mathrm{b}}$ \\
$\mathrm{CCl}_{4}+\mathrm{GNPs}$ & $0.770 \pm 0.013^{\mathrm{e}}$ & $4.474 \pm 0.085^{\mathrm{bc}}$ \\
$\mathrm{CCl}_{4}+\mathrm{GNB}$ & $0.986 \pm 0.060^{\mathrm{d}}$ & $4.040 \pm 0.145^{\mathrm{c}}$ \\
$\mathrm{CCl}_{4}+\mathrm{SM}$ & $1.298 \pm 0.032^{\mathrm{c}}$ & $4.139 \pm 0.156^{\mathrm{c}}$ \\
\hline \multicolumn{2}{r}{ There is no significant difference between means have the same letters in the same column, $n=9$ rats, } \\
$(P \leq 0.05)$. CCl CCl $_{4}$ Carbon tetrachloride, G: Ginger, GNPs: Ginger nano particles, GNB: Ginger nano- base, \\
\multicolumn{2}{r}{ SM: Silymarin }
\end{tabular}

Table 6. Serum total antioxidant capacity (TAC) level, hepatic Catalase (CAT) and hepatic superoxide dismutase (SOD) activities in the experimental groups (mean $\pm \mathrm{SE}$ )

\begin{tabular}{llll}
\hline Parameters/Groups & TAC (mmol/I) & CAT (U/g) & SOD (U/g) \\
\hline Control & $1.496 \pm 0.003^{\mathrm{a}}$ & $0.924 \pm 0.003^{\mathrm{a}}$ & $249.75 \pm 2.563^{\mathrm{a}}$ \\
$\mathrm{CCl}_{4}$ & $0.686 \pm 0.008^{\mathrm{e}}$ & $0.655 \pm 0.002^{\mathrm{e}}$ & $132.51 \pm 1.344^{\mathrm{e}}$ \\
$\mathrm{CCl}_{4}+\mathrm{G}$ & $1.224 \pm 0.034^{\mathrm{d}}$ & $0.875 \pm 0.001^{\mathrm{d}}$ & $168.24 \pm 1.238^{\mathrm{d}}$ \\
$\mathrm{CCl}_{4}+\mathrm{GNPS}$ & $1.342 \pm 0.013^{\mathrm{c}}$ & $0.904 \pm 0.007^{\mathrm{b}}$ & $173.73 \pm 1.669^{\mathrm{d}}$ \\
$\mathrm{CCl}_{4}+\mathrm{GNB}$ & $1.349 \pm 0.0197^{\mathrm{c}}$ & $0.886 \pm 0.003^{\mathrm{c}}$ & $188.11 \pm 2.387^{\mathrm{c}}$ \\
$\mathrm{CCl}_{4}+\mathrm{SM}$ & $1.439 \pm 0.011^{\mathrm{b}}$ & $0.898 \pm 0.002^{\mathrm{b}}$ & $199.49 \pm 2.027^{\mathrm{b}}$ \\
\hline \multicolumn{2}{r}{ There is no significant difference between means have the same letters in the same column, $n=9$ rats, } \\
$\left(P \leq\right.$ 0.05). CCl . Carbon tetrachloride, G: Ginger, GNPs: Ginger nano particles, GNB: Ginger nano- base, $^{\text {SM: Silymarin }}$
\end{tabular}

Hikal et al. showed a significant lowering in serum TAC and hepatic SOD and CAT activities after injection with $\mathrm{CCl}_{4}(1 \mathrm{ml} / \mathrm{kg}$ B.W $)$ in comparison with normal group, which go hand in hand with our results [50]. TAC points to all circumstances of the defense system against oxidation in body and has the powerful effect on diverse ROS production and elevated tendency to oxidative injury [66]. $\mathrm{CCl}_{4}$ metabolism through cytochrome P450 enzyme system increase the oxidative stress in the body and in turn the defense antioxidant system try to scavenge these free radical, but excessive production and increased liberation of oxidant may lead to metabolic exhaustion and disruption of the antioxidant system, loss of homeostasis and finally oxidative destruction occur [3].

It was supposed that GNPs act as potent antioxidant compared to ginger extract. This may be attributed to that GNPs hold shogoals in bind shape compared to those carried by ginger extract that occur in free form. So that, GNPs carried low quantities of shogoals that required for acquiring the same effect on the hepatocytes compared with ginger extract. Shogaols organize many antioxidants and detoxication enzymes genetic expression $[55,15]$.

Ginger has high antioxidant activity which was imputed to its high constituent of polyphenol components such as ([6]-gingerol and it's derivatives) and diarylheptanoids, which possess a potent antioxidant activity [72]. The study of Hemieda et al. confirmed that, the antioxidant compounds of ginger were able to inhibit lipid peroxidation, scavenge the free radical such as $\mathrm{NO}$, and suppress the pro-inflammatory mediator NO production by partially inhibiting enzymatic activity of inducible NO synthase [8].

\subsection{Microscopic Examination of Liver Tissues in Experimental Groups Intoxicated by $\mathrm{CCl}_{4}$}

The results of microscopic examination in our study provided supportive evidence for biochemical analysis. The histological examination of liver tissue from control rats detected normal hepatocyte structure (Fig. 4 A). Furthermore, the liver tissue from $\mathrm{CCl}_{4}$ group revealed focal hepatocellular necrosis and apoptosis associated with mononuclear inflammatory cells infiltration (Fig. 4 B).

Liver section from $\mathrm{CCl}_{4}+\mathrm{G}$ group showed congestion of central vein and slight vacuolization of some hepatocytes (Fig. $5 \mathrm{~A}$ ). Meanwhile, $\mathrm{CCl}_{4}+\mathrm{GNPS}$ and $\mathrm{CCl}_{4}+\mathrm{GNB}$ groups revealed slight cytoplasmic vacuolization of centrilobular hepatocytes (Figs. $5 \mathrm{~B}$ and $6 \mathrm{~A}$ ), respectively. Congestion of central vein and 
hepatic sinusoids was detected in $\mathrm{CCl}_{4}+\mathrm{SM}$ group (Fig. 6 B).

The microscopic examination provided supportive evidence for the hepatotoxic effect of $\mathrm{CCl}_{4}$ that was evidenced by focal hepatocellular necrosis and apoptosis associated with mononuclear inflammatory cells infiltration, which agreed with previous studies $[73,74]$.

The toxic effects of $\mathrm{CCl}_{4}$ on liver that may ended by apoptosis or necrosis of hepatic cells is attributed to oxidative stress generated from CYT P450 metabolism by the highly reactive free radicals as $\mathrm{CCl} 3$ and $\mathrm{CCl} 3 \mathrm{O} 2$. These free radicals invade many molecules causing peroxidation of fatty acids of phospholipid, diminish of membrane integrity, leakage of liver enzymes, inflammation and finally liver injury. Prolonged liver injury leads to

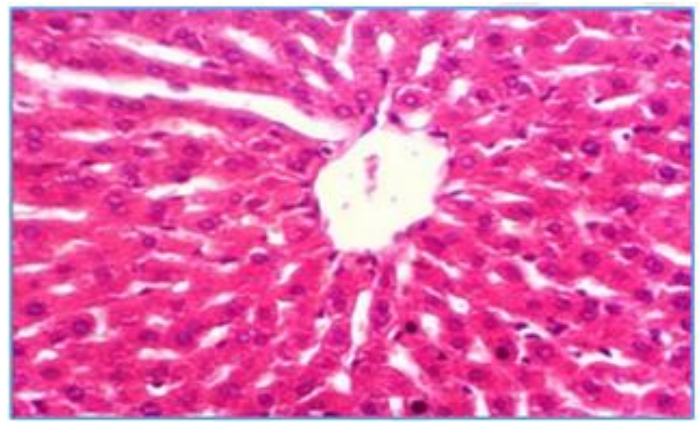

4(A) the development of liver fibrosis and cirrhosis [75].

We observed that ginger protected the architecture of hepatic tissue from damage by $\mathrm{CCl}_{4}$ that induced liver necrosis, this effect may be owing to the presence of phenolic components as gingerols and shogoals which have antioxidant properties and are able to renewed endogenous antioxidant capacity with down regulating of the inflammatory response.

In the study of Bakr et al., the ginger nanoparticles- treated group followed by injection with $\mathrm{CCl}_{4}$ showed more hepatoprotective and antioxidant impact than native ginger group, this may be due to that GNPs can afford digestion in stomach and intestine which enhance the delivery of nanoparticles and it's bioavailability within the hepatocytes. So, nanoparticles can reach to liver in considerable amounts [15].

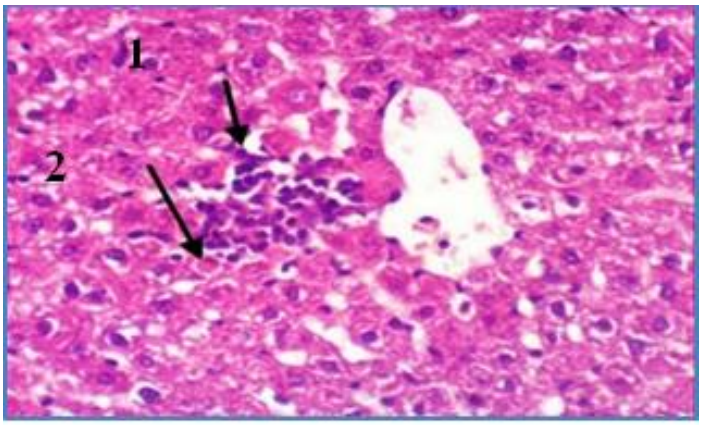

4(B)

Fig. 4. (A): Liver section of rat from normal group showing the normal histological structure of hepatic lobule. (B): Liver section of rat from $\mathrm{CCl}_{4}$ group showing focal hepatocellular necrosis (1) and apoptosis associated with mononuclear inflammatory cells infiltration (2). (H \& E X 400)

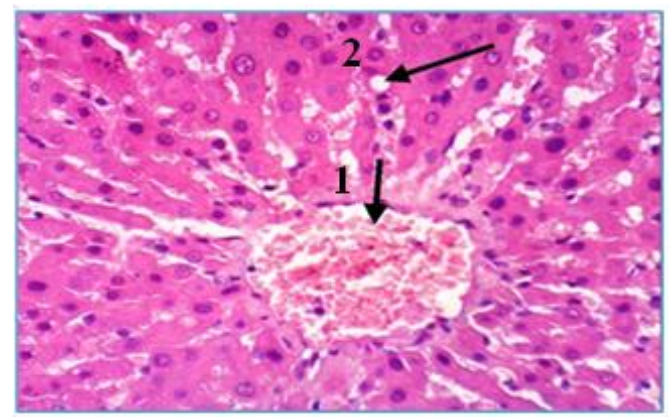

5(A)

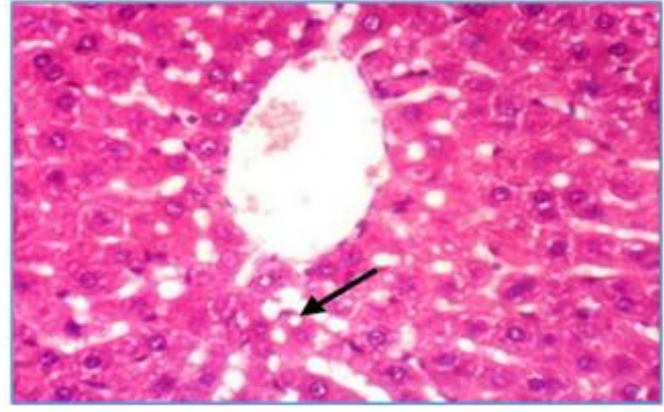

5(B)

Fig. 5. (A): Liver section of rat from $\mathrm{CCl}_{4}+\mathrm{G}$ group showing congestion of central vein (1) and slight vacuolization of some hepatocytes (2). (B): Liver section of rat from $\mathrm{CCl}_{4}+\mathrm{GNPs}_{\text {group }}$ showing slight cytoplasmic vacuolization of centrilobular hepatocytes (H \& E X 400) 


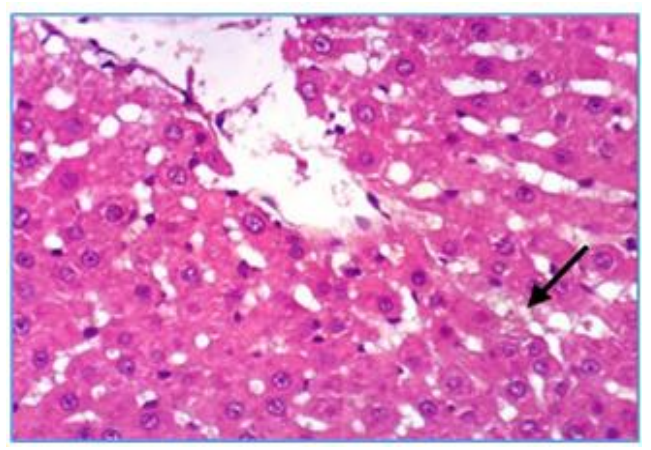

6(A)

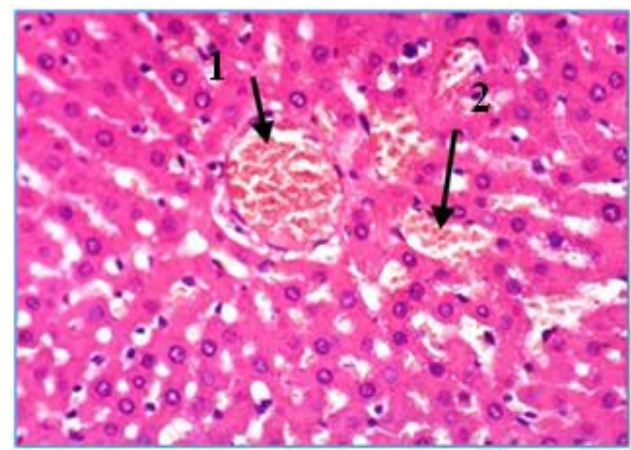

6(B)

Fig. 6. (A): Liver section of rat from $\mathrm{CCl}_{4}+\mathrm{GNB}$ group showing slight cytoplasmic vacuolization of sporadic hepatocytes.(B): Liver section of rat from $\mathrm{CCl}_{4}+\mathrm{SM}$ group showing congestion of central vein (1) and hepatic sinusoids (2) (H \& E X 400)

Pretreatment with silymarin inhibit liver necrosis and apoptosis caused by $\mathrm{CCl}_{4}$. Silymarin is a well-documented hepatoprotective agent, it comprises of flavonolignans complex and it is known for its antioxidant, anti inflammatory, antifibrotic impacts on the liver tissue. Also, it plays an important role as membrane-stabilizing agent, free radicals scavenging and suppression of lipid peroxidation and modulation of hepatocyte $\mathrm{Ca}+2[67,75]$.

\subsection{Microscopic Examination of Kidneys Tissues in Experimental Groups Intoxicated by $\mathrm{CCl}_{4}$}

Kidney section of rats from control group showed normal renal tissues and histological structure of renal parenchyma, well defined glomeruli and Bowman's capsule, normal renal tubuli and

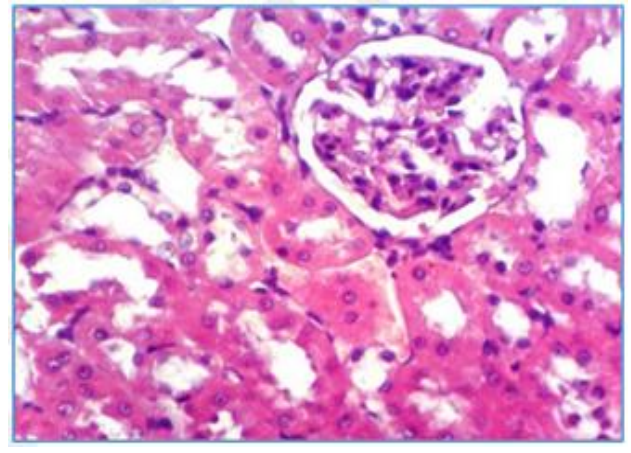

7(A) normal interstitial tissue with normal blood vessels (Fig. 7 A). Intraperitoneal injection with $\mathrm{CCl}_{4}(1 \mathrm{ml} / \mathrm{kg}$ B.W $)$ caused vacuolization of epithelial lining renal tubules and endothelial lining glomerular tuft as well as periglomerular inflammatory cells infiltration as shown in (Fig. 7 B). Slight vacuolization of epithelial lining renal tubules and endothelial lining glomerular tuft were found in all treated groups (Figs. $8 \mathrm{~A}, 8 \mathrm{~B}$, 9A, 9B).

The changes occur in kidneys tissue by $\mathrm{CCl}_{4}$ were induced by oxygen-derived free radicals and $\mathrm{CCl}_{4}$ metabolites produced from $\mathrm{CCl}_{4}$ metabolism by CYT P450 enzymes in renal cortex leading to lipid peroxidation in kidney cells. The changes of antioxidant status with $\mathrm{CCl}_{4}$ may potentially cause nephropathies or renal disorders [61].

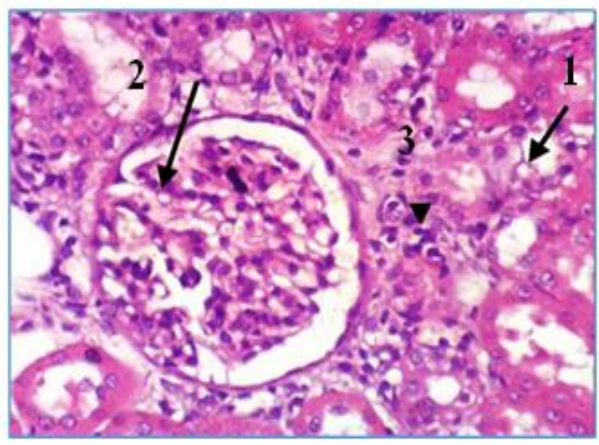

7(B)

Fig. 7. (A): Kidney section of rat from normal group showing the normal histological structure of renal parenchyma. (B): Kidney section of rat from $\mathrm{CCl}_{4}$ group showing vacuolization of epithelial lining renal tubules (1) and endothelial lining glomerular tuft (2) as well as periglomerular inflammatory cells infiltration (3) (H \& E X 400) 


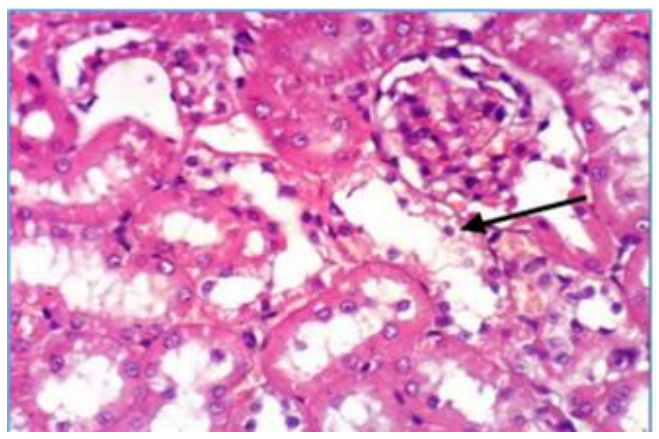

8(A)

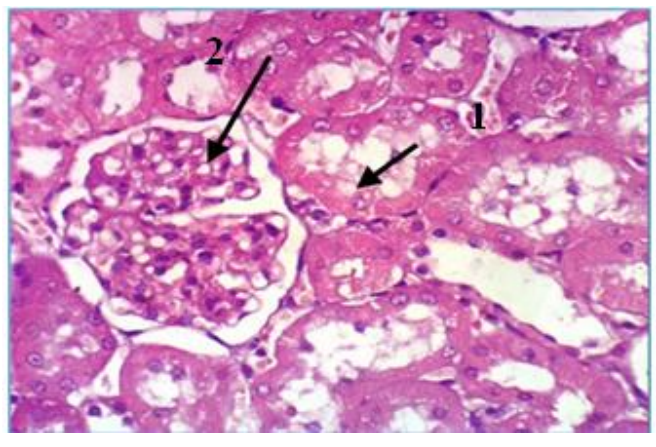

8(B)

Fig. 8. (A): Kidney section of rat from $\mathrm{CCl}_{4}+\mathrm{G}$ group showing slight vacuolization of epithelial lining renal tubules.(B): Kidney section of rat from $\mathrm{CCl}_{4}+\mathrm{GNPs}$ group showing slight vacuolization of epithelial lining renal tubules (1) and endothelial lining glomerular tuft (2) (H \& E X 400)

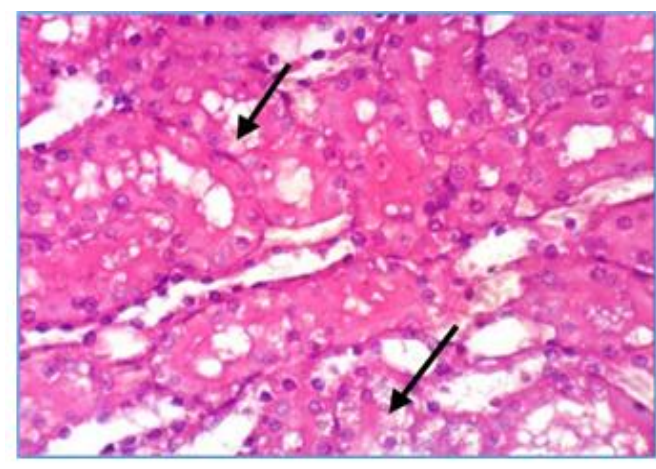

$9(\mathrm{~A})$

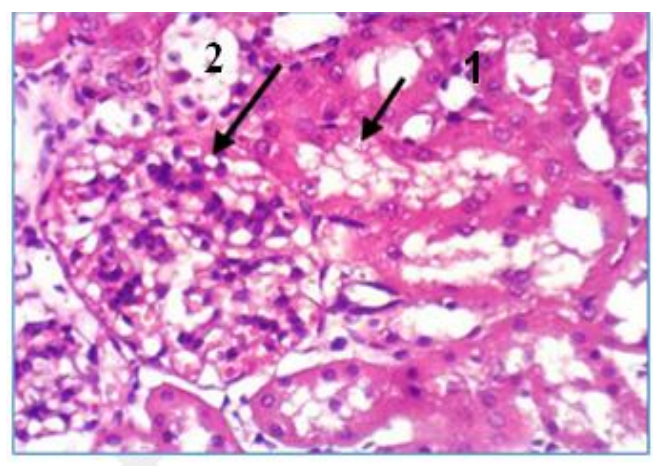

9(B)

Fig. 9. (A): Kidney section of rat from $\mathrm{CCl}_{4}+\mathrm{GNB}$ group showing slight vacuolization of epithelial lining renal tubules (B): Kidney section of rat from $\mathrm{CCl}_{4}+\mathrm{SM}$ group showing vacuolization of epithelial lining renal tubules (1) and endothelial lining glomerular tuft (2) (H \& EX 400)

The preventive effect of ginger and silymarin contra $\mathrm{CCl}_{4}$ in organs including kidney, is attributed to the antioxidant, anti-inflammatory, scavenging the free radicals and membrane stabilizing effect [53].

Administration of GNPs and GNB resulted in enhancements in microscopically structures of kidneys tissues in rats as in liver tissue that impaired by $\mathrm{CCl}_{4}$ due to antioxidant, antiapoptotic effect of them [15].

\section{CONCLUSION}

From our study we concluded that, administration of $\mathrm{CCl}_{4}$ for 8 weeks led to hepatotoxicity and nephrotoxicity. Co-administration of G, GNPs, GNB and SM with $\mathrm{CCl}_{4}$ protect the liver and kidney tissues from damage due to their high content of phenols and flavonoids, which enhance the antioxidant activities and protect against oxidative stress and lipid peroxidation. GNPs and GNB are more hepatoprotective and reno-protective against $\mathrm{CCl}_{4^{-}}$induced toxicity relative to the native ginger which may be due to their increased solubility and bioavailability.

\section{ETHICAL APPROVAL}

All authors hereby declare that "Principles of laboratory animal care" (NIH publication No. 8523 , revised 1985) were followed, as well as specific national laws where applicable. All experiments have been examined and approved by the appropriate ethics committee" 


\section{COMPETING INTERESTS}

Authors have declared that no competing interests exist.

\section{REFERENCES}

1. Sun J, Wen X, Liu J, Kan J, Qia, C, Wu C, Jin, C. Protective effect of an arabinogalactan from black soybean against carbon tetrachloride-induced acute liver injury in mice. Biological Macromolecules. 2018;1- 33.

2. Elzwi S. Effect of Zingiber officinale (Ginger) extract on acetaminophen induced hepatotoxicity in mice. Pharmaceutical Methods. 2019;10(1):2730.

3. Popović D, Kocić G, Katić V, Jović Z, Zarubica A, Veličković, LJ, Nikolić V, Jović A, Kundalić B, Rakić V, Ulrih NP, Skrt M, Sokolović D, Dinić L, Stojanović, $M$, Milosavljević A, Filip V, Sokolović D. Protective effects of anthocyanins from bilberry extract in rats exposed to nephrotoxic effects of carbon tetrachloride, Chemico-Biological Interactions. 2019; 304:61-72.

4. Fahmy MA, Diab KA, Abdel-Samie NS, Omara EA, Hassan ZM. Carbon tetrachloride induced hepato/renal toxicity in experimental mice: antioxidant potential of Egyptian Salvia officinalis $\mathrm{L}$ essential oil. Environmental Science and Pollution Research. 2018;25:2785827876.

5. Ghadi FE, Ghara AR, Rodbari Z. Ameliorating effect of gamma irradiated chicory against carbon tetra-chloride induced kidney and testis damage in rat. Iranian Journal of Health Sciences. 2019; 7(1): 9-17.

6. Ayanniyi RO, Olumoh-Abdul HA, Ojuade FI, Abdullahi R, Anafi SB. The protective effect of Croton zambesicus against carbon tetrachloride-induced renal toxicity in rats. Iranian Journal of Toxicology. 2019; 13 (1):5 - 8.

7. Akbari A, Nasiri K, Heydari M, Nimrouzi M, Afsar T. Ameliorating potential of ginger (Zingiber officinale Roscoe) extract on liver function and oxidative stress induced by ethanol in male rats. Zahedan Journal of Research in Medical Science. 2019;21(2): 1- 8 .
8. Hemieda FAE, El-Kholy WM, Masud ASA. Evaluating the protective impact of ginger extract against ciprofloxacin-induced hepatotoxicity in male albino rats. IOSR Journal of Pharmacy and Biological Sciences. 2019;14(1):23-30.

9. Shirpoor A, Rezaei F, Fard AA, Afshari AT, Gharalari FH, Rasmi Y. Ginger extract protects rat's kidneys against oxidative damage after chronic ethanol administration. Biomedicine \& Pharmacotherapy. 2016;84:698-704.

10. Al Shammari AMN. Protective effect of ginger (Zingiber officinale) consumption against kidney damage in rats. Life Science Journal. 2018;15(1):80-85.

11. Korni FMM, Khalil F. Effect of ginger and its nanoparticles on growth performance, cognition capability, immunity and prevention of motile Aeromonas septicaemia in Cyprinus carpio fingerlings. Aquaculture Nutrition. 2016;23:1492-1499.

12. Zhang $M$, Viennois $E$, Prasad $M$, Zhang $Y$, Wang L, Zhang Z, Han MK, Xiao B, Xu C, Srinivasan S, Merlin D. Edible gingerderived nanoparticles: A novel therapeutic approach for the prevention and treatment of inflammatory bowel disease and colitisassociated cancer. Biomaterials. 2016;162.

13. Mehanna MS, Al-Shahed FNM, Taha MK. Histological study of effect of exposure to emamectin benzoate on the kidney of adult male albino rats and the possible protective effect of ginger nanoparticles. The Egyptian Journal of Hospital Medicine. 2019;76(1):3299-3306.

14. Abdu SB, Abdu F, Khalil WKB. Ginger nanoparticles modulate the apoptotic activity in male rats exposed to dioxininduced cancer initiation. International Journal of Pharmacology. 2017;13:946957.

15. Bakr AF, Abdelgayed SS, EL-Tawil OS, Bakeer AM. Assessment of ginger extract and ginger nanoparticles protective activity against acetaminophen-induced hepatotoxicity and nephrotoxicity in rats. Pakistan Veterinary Journal. 2019;1-8.

16. Zhang $H$, Wang $Q$, Sun $C$, Zhu $Y$, Yang $Q$, Wei Q, Chen J, Deng W, Frimpong MA, Yu J, Xu X. Enhanced oral bioavailability, antitumor activity and hepatoprotective effect of 6-shogaol loaded in a type of novel micelles of polyethylene glycol and linoleic 
acid conjugate. Pharmaceutics. 2019; 11(107):1- 16.

17. Hassan SK, Mousa AM, Eshak MG, Farrag $\mathrm{AH}$, Badawi AM. Therapeutic and chemo preventive effects of nano curumin against diethylnitrosamino induced hepatocellular carcinoma in rats. International Journal of Pharmacy and Pharmaceutical Sciences. 2014; 6:54- 62.

18. Sharifi-Rigi1 A, Heidarian E. Protective and anti-inflammatory effects of silymarin on paraquat-induced nephrotoxicity in rats. Journal of Herbmed Pharmacology. 2019; 8:28 - 34.

19. Mashayekhi M. Renoprotective effect of silymarin on gentamicin-induced nephropathy. African Journal of Pharmacy and Pharmacology. 2012;6(29): 2241-2246.

20. Amin KA, Ahmed RR, Hozayen WG, Antar A. Renoprotective and antioxidant effects of silymarin and propolis on diclofenac sodium - induced renal toxicity in rats. International Journal for Pure and Applied Bioscience. 2017;5(2):31-42.

21. Cengiz M. Renoprotective effects of Silybum marianum (L.) Gaertn (Silymarin) on thioacetamide-induced renal injury: Biochemical and histopathological approach. Pak. J. Pharm. Sci. 2018;31(5): 2137-2141.

22. Korni FMM, Khalil F. Effect of ginger and its nanoparticles on growth performance, cognition capability, immunity and prevention of motile Aeromonas septicaemia in Cyprinus carpio fingerlings. 2016;23:1492-1499.

23. Thakur PY, Ram MY, Dinesh PS. Mechanical milling: A top down approach for the synthesis of nanomaterials and nanocomposites. Nanoscience and Nanotechnology. 2012;2:22-48.

24. Eren D, Betul YM. Revealing the effect of 6-gingerol, 6-shogaol and curcumin on mPGES-1, GSK-3 $\beta$ and $\beta$-catenin pathway in A549 cell line. Chemico-Biological Interactions. 2016;1-26.

25. Singleton VL, Orthofer F, LamuelaRaventos RM. Analysis of total phenols and other oxidation substrates and antioxidants by means of folin ciocalteu reagent. Methods in Enzymology. 1999;299:152-178.

26. Arvouet-Grand A, Vennat B, Pourrat A, Legret $P$. Standardisation d'un extrait de propolis et identification des principaux constituants. Journal de Pharmacie de Belgique. 1994;49:462-468.

27. Cafino EJ, Marcelina BL, Eufrocinio CM. NA simple HPLC Method for the Analysis of [6]-Gingerol Produced by Multiple Shoot Culture of Ginger (Zingiber officinale). International Journal of Pharmacognosy and Phytochemical Research. 2016;8(1): 38-42.

28. Sreelatha S, Padma PR, Umadevi M. Protective effects of Coriandrum sativum extracts on carbon tetrachloride-induced hepatotoxicity in rats. Food and Chemical Toxicology. 2009;47:702-708.

29. Murray RL. alanine aminotransferase, Kaplan A et al Clin Chem The C.V. Mosby Co, St Louis, Toronto, Princeton. 1984; 1261-1266.

30. Belfield A, Goldberg DM. Revised assay for serum phenyl phosphatase activity using 4- amino - antipyrine. Enzyme. 1971;12(5):561-573.

31. Murray RL. Creatinine, Kaplan A, et al. Clin Chem the C.V. Mosby Co, St Louis, Toronto, Princeton. 1984;1261-1266.

32. Kaplan A. Urea, Kaplan A, et al. Clin Chem The CV Mosby Co St Louis. Toronto. Princeton. 1984;1257-1260:437-418.

33. Fossati P, Prencipe L, Berti G. Use of 3, 5dichloro-2-hydroxybenzenesulfonicacid/4aminophenazone chromogenic system in direct enzymic assay of uric acid in serum and urine. Clinical Chemistry. 1980;26: 227-231.

34. Pergande M, Jung K. Sandwich Enzyme Immunoassay of Cystatin C in Serum with Commercially Available Antibodies. Clinical Chemistry. 1993;39(9):18851890.

35. Dowlati $Y$, Herrmann N, Swardfager W, Liu H, Sham L, Reim EK, Lanctôt KL. A metaanalysis of cytokines in major depression. Biological Psychiatry. 2010; 67:446-457.

36. Garabedian BS, Poole S, Allchorne A, Winter J, Woolf CJ. Contribution of interleukin- 1 to the inflammation-induced increase in nerve growth factor levels and inflammatory hyperalgesia. British Journal of Pharmacology. 1995;115:1265-1275.

37. Koracevic D, Koracevic G, Djordjevic V, Andrejevic S, Cosic V. Method for the measurement of antioxidant activity in human fluids, journal of clinical pathology. 2001;54:356-361. 
38. Aebi $\mathrm{H}$. Oxidoreductases acting on groups other than $\mathrm{CHOH}$ : catalase. Methods in Enzymology. 1984;121-126.

39. Nishikimi M, Rao NA, Yagi $K$. The occurrence of superoxide anion in the reaction of reduced phenazine methosulfate and molecular oxygen. Biochemical and biophysical research communication. 1972;(2) 46:849- 854.

40. Montgomery HAC, Dymock JF. The determination of nitrite in water. Analyst. 1961;86:414-416.

41. Satoh K. Serum lipid peroxide in cerebrovascular disorder determined by a new colorimetric method. Clinica Chimica Acta. 1978;90:37-43.

42. Bancroft JD, Gamble M. Theory and practice of histological techniques. $6^{\text {th }}$ ed. Philadelphia: Churchill Livingstone, Elsevier; 2008.

43. Levesque S. SPSS programming and data management: A Guide for SPSS and SAS users, fourth edition. Spss Inc, Chicago; 2007.

44. Rahimi HR, Nedaeinia R, Shamloo AS, Nikdoust S, Oskuee RK. Novel delivery system for natural products: Nanocurcumin formulations. Avicenna Journal of Phytomedicine. 2016;6(4):383-398.

45. Mošovská $S$, Nováková $D$, Kaliňák $M$. Antioxidant activity of ginger extract and identification of its active components. Acta Chimica Slovaca. 2015;8(2):115119.

46. Wijayanti II, Budiharjo A, Pangastut A, Prihapsara F, Artanti AN. Total phenolic content and antioxidant activity of ginger extract and SNEDDS with eel fish bone oil (Anguilla spp.). Nusantara Bioscience. 2018;10(3):164-169.

47. Mojzer EB, Hrnॅ̌cǐc MK, Škerge M, Knez $Z$, Bren U. Polyphenols: Extraction methods, antioxidative action, bioavailability and anticarcinogenic effects. Molecules. 2016;21(901):1- 38.

48. Shirin APR, Prakash J. Chemical composition and antioxidant properties of ginger root (Zingiber officinale). Journal of Medicinal Plants Research. 2010;4(24): 2674-2679.

49. Bellassoued K, Hsouna AB, Athmouni K, Pelt JV, Ayadi MF, Rebai T, Elfeki A. Protective effects of Mentha piperita L. Leaf essential oil against CCl4induced hepatic oxidative damage and renal failure in rats. Lipids in Health and Disease. 2018; 17(9):1-14.

50. Hikal AH, Abd El-Fatta HM, El-Sheik NM, Refaie AA. Comparative study of marjoram (Origanum majorana L.) and silymarin (Silybum marianum L.) extract against carbon tetrachloride induced hepatic injury. World Journal of Pharmacy and Pharmaceutical Sciences. 2018;7(8):196992.

51. Ullah $\mathrm{H}$, Khan A, Baig MW, Ullah $\mathrm{N}$, Ahmed N, Tipu MK, Ali H, Khan S. Poncirin attenuates CCL4-induced liver injury through inhibition of oxidative stress and inflammatory cytokines in mice. BMC Complementary Medicine and Therapies. 2020;20(115):1-14.

52. Okda TM, Abd-Alhaseeb MM, Barka K, Ragab NM. Ginger potentiates the effects of silymarin on liver fibrosis induced by CCL4: The role of galectin-8, European Review for Medical and Pharmacological Sciences. 2019;23:885-891.

53. Ojarudi M, Moradi A, Hajihosseini R, Mazani M, Rezagholizadeh L. Hepatoprotective and antioxidant a ctivities of combination of Cinnamomum zeylanicum and Zingiber officinale in ccl4 intoxicated rats. Journal of Kerman University of Medical Sciences. 2020; 27(1):1- 13.

54. Wang B, Zhuang X, Deng ZB, Jiang H, Mu $J$, and Wang $Q$, et al. Targeted drug delivery to intestinal macrophages by bioactive nanovesicles released from grapefruit. Molecular Therapy. 2014;22: 522- 34.

55. Zhuang X, Deng ZB, Mu J, Zhang L, Yan J, Miller D, Feng W, McClain CJ, Zhang HG. Ginger-derived nanoparticles protect against alcohol-induced liver damage. Journal of Extracellular Vesicles. 2015; 4.

56. Javed S, Ahsan W, Kohli K. Pharmacological influences of natural products as bioenhancers of silymarin against carbon tetrachloride-induced hepatotoxicity in rats. Clinical Phytoscience. 2018;4-18.

57. Zaki DA, Abdel-Ghany AS, Gomaa A. Therapeutic effect of milk thistle (Silybum marianum $\mathrm{L}$ ) seeds on carbon tetrachloride - induced hepatotoxicity in rats. Alexandria Science Exchange Journal. 2019;40(1):2029. 
58. Bektur NE, Sahin E, Baycu C, Unver G. Protective effects of silymarin against acetaminophen-induced hepatotoxicity and nephrotoxicity in mice. Toxicology and Industrial Health. 2013;1-12.

59. Abdel Maksoud HA, Abdel Magid AD, Mostafa YM, Elharrifc MG, Sorour RI, Sorour MI. Ameliorative effect of liquorice extract versus silymarin in experimentally induced chronic hepatitis: A biochemical and genetical study, Clinical Nutrition Experimental. 2019;23: 69-79.

60. Kheiripour N, Karimi J, Khodadadi I, Tavilani H, Goodarzi MT, Hashemnia M. Hepatoprotective effects of silymarin on liver injury via irisin upregulation and oxidative stress reduction in rats with type 2 diabetes. Iran J Med Sci. 2019;44(2): 108-117.

61. Akram MA, Tembhre M, Jabeen R, Khalid S, Sheikh MA, Jan A, Farooq U, Amin M. Defensive role of Rosmarinus officinalis in carbon tetrachloride-induced nephrotoxicity and oxidative stress in rats. Bulletin of the National Research Centre. 2019; 43(50):1- 10.

62. Tousson E, Keshta ATH, Hussein Y, Fekry RM, Abo-Ghaneima WK. Renal protective effect of Ginkgo biloba and I-carnitine extracts against pentylenetetrazol induced toxicity, oxidative stress, injury and proliferation alternation in epileptic rats. Annual Research \& Review in Biology. 2019;32(2):1-13.

63. Abdulhameed IS, Al-Mohamadamin DFH, Abed AB, Abid WB. The effect of ginger plant (Zingiber officinale) aqueous extract on function and histological structure of kidney in mice treated with carbon tetrachloride. International Journal of ChemTech Research. 2017;10(12):208219.

64. Joshi D, Srivastav SK, Belemkar S, Dixit VA. Zingiber officinale and 6gingerol alleviate liver and kidney dysfunctions and oxidative stress induced by mercuric chloride in male rats: A protective approach. Biomedicine \& Pharmacotherapy. 2017;91:645-655.

65. EL. Sayed, MGA, Farag EAH, Nasr HM. Protective effects of prebiotic (resistant maltodextrin) and silymarin against toxicity of carbon tetrachloride in liver rat and kidney. International Journal of
Pharmacology and Toxicology. 2020;8(1): 15-28.

66. Meng X, Wang Z, Liang S, Tang Z, Liu J, Xin $Y$, Kuang $H$, Wang $Q$. Hepatoprotective effect of a polysaccharide from Radix Cyathulae officinalis Kuan against $\mathrm{CCl} 4$-induced acute liver injury in rat, International Journal of Biological Macromolecules. 2019;1- 22.

67. Abdel Salam OME, Sleem AA, Omara EA, Hassan NS. Effect of ribavirin alone or combined with silymarin on carbon tetrachloride induced hepatic damage in rats. Drug Target Insights. 2007;2:1927.

68. Mansour DF, Abdallah HM, Ibrahim BMM, Hegazy RR, Esmail RSE, Abdel-Salam LO. The carcinogenic agent diethylnitrosamine induces early oxidative stress, inflammation and proliferation in rat liver stomach and colon: Protective Effect of Ginger Extract. Asian Pacific Journal of Cancer Prevention. 2019;20:25512561.

69. Soliman MM, Elfeky AMS. Studies on the biochemical and molecular effects of some natural herbs on experimentalinduced breast cancer in wistar rats. Nat $\mathrm{J}$ Physio, Pharm Pharmacol. 2016;6:534958.

70. Sha J, Song J, Yu M, Zhao X, Wang H, Zhang $\mathrm{Y}$, Suo $\mathrm{H}$. Polyphenolic extracts from Wushan tea leaves attenuate hepatic injury in $\mathrm{CCl}_{4}$-treated mice. Journal of Functional Foods. 2020;66:1-8.

71. Hasan IH, El-desouky MA, Abd-elaziz GM, Hozayen WG. Protective effects of Zingiber officinale against carbon tetrachloride induced liver fibrosis. International Journal of Pharmacy and Pharmaceutical Sciences. 2016;8:77-381.

72. Attia AMM, Ibrahim FAA, Nabil GM, Aziz SW. Antioxidant effects of ginger (Zingiber officinale Roscoe) against lead acetateinduced hepatotoxicity in rats. African Journal of Pharmacy and Pharmacology. 2013;7(20):1213-1219.

73. Shokrzadeh $M$, jouybari HB, Hosseinpour $M$, ziar A, Habibi E. Antioxidant and protective effect of hydroalcoholic extract of Celtis australis $\mathrm{L}$. on $\mathrm{CCl}_{4}$ induced hepatotoxicity. Pharmaceutical and Biomedical Research. 2019;4(3):2631. 
74. Lin TA, Ke BJ, Cheng CS, Wang JJ, Wei $B L$, Lee CL. Red quinoa bran extracts protects against carbon tetrachlorideinduced liver injury and fibrosis in mice via activation of antioxidative enzyme systems and blocking TGF- $\beta 1$ Pathway. Nutrients. 2019;11(395):1 -14.
75. Eltahir HM, Fawzy MA, Mohamed EM, Alrehany MA, Shehata AM, Abouzied MM. Antioxidant, anti-inflammatory and antifibrotic effects of Boswellia serrategum resin in $\mathrm{CCl} 4$-induced hepatotoxicity. Experimental and Therapeutic Medicine. 2020;19:1313-1321.

(c) 2020 Abd-Elrhman et al.; This is an Open Access article distributed under the terms of the Creative Commons Attribution License (http://creativecommons.org/licenses/by/4.0), which permits unrestricted use, distribution, and reproduction in any medium, provided the original work is properly cited.

Peer-review history:

The peer review history for this paper can be accessed here: http://www.sdiarticle4.com/review-history/59109 